\title{
PENGEMBANGAN MODUL PEMBELAJARAN TEMATIK PJOKTEMA DIRIKU PADA PESERTA DIDIK KELAS 1 SD DI KECAMATAN BULELENG
}

\author{
Komang Agus Indrayasa ${ }^{1}$, I Putu Panca Adi ${ }^{2}$, Ni Putu Dwi Sucita Dartini ${ }^{3}$ \\ 1,2,3 Universitas Pendidikan Ganesha \\ E-mail: indrakaiy@gmail.com¹, pancaadi@undiksha.ac.id², dwisucita@gmail.com³ \\ DOI: https://doi.org/10.36526/kejaora.v6i1.1142
}

\begin{abstract}
ABSTRAK
Penelitian ini bertujuan untuk mengembangkan modul pembembelajaran tematik PJOK tema diriku pada peserta didik kelas 1 SD di Kecamatan Buleleng. Jenis penelitian ini adalah penelitian pengembangan. Prosedur pengembangan modul pembelajaran tematik PJOK menggunakan model Borg \& Gall hanya sampai tahap 5 yaitu tahap penelitian dan pengumpulan informasi, tahap perencanaan, tahap, mengembangkan bentuk pendahuluan produk, tahap uji lapangan persiapan, dan tahap revisi produk utama. Langkah validasi modul pembelajaran tematik PJOK mengadopsi model Borg \& Gall yaitu: uji lapangan persiapan dan peneliti menambahkan uji ahli isi dan uji ahli media agar penelitian lebih signifikan. Teknik analisis data yang digunakan yaitu deskriptif kuantitatif. Hasil penelitian menunjukkan bahwa validasi modul pembelajaran PJOK ditinjau dari aspek isi oleh ahli isi adalah sangat baik dengan presentase $91,76 \%$. Ahli media berada pada kualifikasi baik dengan presentase $83,33 \%$. Hasil uji lapangan persiapan dari peserta didik memperoleh presentase $96,84 \%$ dan guru PJOK memperoleh presentase $96,85 \%$ berada pada pada kualifikasi sangat baik. Berdasarkan hasil penelitian disimpulkan bahwa modul pembelajaran tematik PJOK tema diriku pada kelas 1 SD di Kecamatan Buleleng layak digunakan ditinjau dari uji ahli isi, uji ahli media dan uji lapangan persiapan. Penelitian ini diharapkan dapat dieksperimenkan untuk mengetahui efektivitas dari modul pembelajaran tematik PJOK.
\end{abstract}

Kata Kunci: Pembelajaran Tematik, PJOK, Modul

\section{PENDAHULUAN}

Pendidikan merupakan salah satu faktor yang penting bagi suatu bangsa. Melalui pendidikan dapat diwujudkan sumberdaya manusia yang berkualitas. Pendidikan adalah usaha sadar untuk mempengaruhi peserta didik agar bisa mengaktualisasikan serta mengembangkan bakat-bakat yang dimilikinya sehingga nantinya mampu menjalani hidup yang baik.(Utama, 2011)

Semua jenjang pendidikan di Indonesia sekarang ini sudah menerapkan kurikulum 2013, termasuk di Sekolah Dasar (SD). Pada jenjang Sekolah Dasar (SD) sudah menggunakan metode tematik terpadu. Pembelajaran tematik merupakan suatu pendekatan yang mengaitkan atau memadukan satu pelajaran dengan pelajaran yang lain yang dikemas menjadi satu tema (Sukayati, 2009). Dalam pembelajaran tematik menggunakan tema sebagai pemersatu kegiatan pembelajaran yang memadukan mata pelajaran sekaligus, untuk memberikan pengalaman yang bermakna bagi peserta didik (Kadir, 2015). Karena peserta didik untuk memahami berbagai konsep yang mereka pelajari selalu melalui pengalaman langsung dan menghubungkannya dengan konsep lain yang telah dikuasainya. Pada peserta didik kelas 1 Sekolah Dasar ada beberapa tema yang dibahas salah satunya yaitu tema "Diriku". Pada tema diriku ini merupakan kegiatan pembelajaran yang mempelajari tentang kehidupan sehari-hari yang berhubungan dengan peserta didik dan teman barunya, organ tubuh manusia, cara merawat tubuh serta mengamati wajah dan mengenal ciri-ciri yang dimiliki peserta didik yang dikaitkan dengan beberapa mata pelajaran. Tema diriku dibagi menjadi 
Jurnal Kejaora: Jurnal Kesehatan Jasmani dan Olah Raga

ISSN: 2541-5042 (Online)

ISSN: 2503-2976 (Print)

Volume 6 Nomor 1, Edisi April 2021

beberapa subtema salah satunya "Aku dan Teman Baru". Pada subtema aku dan teman baru terkaji dalam beberapa mata pelajaran yaitu Matematika, Bahasa Indonesia, PPKn, dan Pendidikan Jasmani Olahraga dan Kesehatan (PJOK).

Pendidikan Jasmani Olahraga dan Kesehatan (PJOK) merupakan suatu proses pembelajaran melalui aktivitas jasmani yang didesain untuk meningkatkan kebugaran jasmani, mengembangkan keterampilan motorik, pengetahuan dan perilaku hidup sehat dan aktif, sikap sportif, dan kecerdasan emosi (Samsudin, 2008). Pembelajaran PJOK bertujuan untuk membantu peserta didik dalam usaha meningkatkan derajat kesehatan dan kebugaran jasmani melalui keterampilan gerak dasar dalam berbagai aktivitas jasmani. Untuk mencapai tujuan PJOK diperlukan motivasi dari peserta didik serta mempertimbangkan kemampuan yang dimiliki peserta didik serta minat secara menyeluruh sehingga peserta didik dapat tumbuh dan berkembang secara sempurna dengan cara yang menyenangkan. (Huraibi, Chabib, Zain \& Indahwati. 2018). Dalam pembelajaran PJOK terdapat beberapa ruang lingkup yaitu, (1) permainan dan olahraga, (2) aktivitas pengembangan, (3) Aktivitas senam, (4) Aktivitas ritmik, (5) aktivitas air, (6) pendidikan luar kelas, (7) kesehatan (Rahayu, 2016).

Tantangan terberat yang dialami oleh guru PJOK adalah menerapkan pembelajaran tematik di sekolah. Berdasarkan dari penyebaran kuisioner dari 10 orang guru PJOK di Kecamatan Buleleng 9 orang $(90 \%)$ diantaranya mengatakan mengalami kesulitan dalam menerapkan pembelajaran tematik PJOK antara lain, (1) kurangnya sosialisasi kepada guru PJOK tentang pembelajaran tematik PJOK, (2) sarana dan prasarana di sekolah juga belum memadai, (3) terbatasnya contoh-contoh kegiatan pembelajaran PJOK berbasis tematik, (4) buku pegangan guru tentang pembelajaran PJOK berbasis tematik masih secara umum dan belum lengkap, (5) proses pembelajaran menggunakan metode daring kurang efektif dalam melaksakan pembelajaran tematik PJOK. Dalam hal ini tentunya guru akan mengalami kesulitan

dalam menerapkan pembelajaran PJOK berbasis tematik. Akan lebih mudah dipahami apabila modul yang dijadikan pegangan untuk guru lengkap dan ada banyak contoh-contoh pembelajaran tematik khusus mata pelajaran PJOK. Hasil observasi juga menunjukkan bahwa 9 dari 10 guru (90\%) berharap agar tersedianya modul pembelajaran tematik PJOK sehingga bisa menerapkan dan mengembangkan pembelajaran PJOK berbasis tematik di sekolah. Dari permasalahan tersebut maka perlu solusi yang tepat untuk mengatasinya. Salah satu alternatif yang tepat adalah dengan tersedianya modul pembelajaran tematik khususnya pembelajaran PJOK kelas 1 SD tema diriku subtema aku dan teman baru melalui model-model permainan yang mencakup perpaduan beberapa mata pelajaran. Pembelajaran tematik adalah penggabungan beberapa materi menjadi satu kepaduan dalam lingkup SD atau MI meliputi, Pendidikan Pancasila dan Kewarganegaraan (PPKN), IImu Pengetahuan Sosial (IPS), IImu Pengetahuan Alam (IPA), Matematika (MM), Bahasa Indonesia (BI), Seni Budaya dan Prakarya (SBdP) dan Pendidikan Jasmani Olahraga dan Kesehatan (PJOK) (Maulana Arafat Lubis, 2016). Pembelajaran tematik merupakan kegiatan pembelajaran dengan mengkombinasikan beberapa materi kedalam satu tema (Mukhlis, 2012). Tujuan dari pembelajaan tematik adalah untuk memudahkan peserta didik dalam memahami dan mendalami konsep materi yang bergabung dalam tema. Manfaat yang akan diperoleh dari pembelajaran tematik ini yaitu peserta didik dan guru mampu berinteraksi secara dekat dan tepat sehingga proses pembelajaran akan menjadi efektif dan efesien (Pgmi et al., 2015). Dalam pembelajaran tematik ini memiliki beberapa keunggulan yaitu: (1) pengalaman dan kegiatan akan selalu relevan dengan perkembangan peserta didik, (2) kegiatankegiatan pembelajaran yang dipilih sesuai dengan kebutuhan dan minat peserta didik, (3) seluruh kegiatan belajar lebih bermakna bagi peserta didik sehingga pembelajaran akan bertahan lebih lama (Tirtoni, 2018). Adapun karakteristik pembelajaran tematik di sekolah dasar yaitu (1) berpusat pada peserta 
Jurnal Kejaora: Jurnal Kesehatan Jasmani dan Olah Raga

ISSN: 2541-5042 (Online)

ISSN: 2503-2976 (Print)

Volume 6 Nomor 1, Edisi April 2021

didik (2) dapat pengalaman langsung, (3) pemisahan mata pelajaran tidak begitu jelas, (4) fleksibel , (5) belajar sambil bermain, (6) menyajikan konsep dari berbagai pelajaran (Nafi et al., 2016)

Berdasarkan uraian diatas peneliti merasa terdorong untuk mengadakan penelitian yang berjudul "Pengembangan Modul Pembelajaran Tematik PJOK Tema Diriku pada Peserta Didik Kelas 1 SD di Kecamatan Buleleng".

\section{METODE}

Penelitian ini menggunakan metode Reasearch and Development (R\&D). Penelitian R\&D pada dasarnya memiliki karakteristik adanya produk yang dihasilkan dari penelitiannya. Model pembuatan produk dalam penelitian pengembangan ini adalah model Borg and Gall sampai pada tahap kelima yaitu (1) reasearch and information collection, (2) plainning, (3) develop preliminary form of product, (4) preliminary field testing, (5) main product revision. Pada penelitian ini tahap pengambilan data hanya sampai pada analisis dan revisi I dikarenakan adanya wabah pandemi covid-19 yang membuat sekolah melakukan pembelajaran secara daring sehingga tidak memungkinkan untuk terjun kelapangan dan melakukan penelitian untuk skala besar.

Data yang diambil pada penelitian ini adalah data kuantitatif. Data tersebut berupa data yang menggambarkan kualitas produk yang meliputi aspek isi dan petunjuk pelaksanaan modul pembelajaran tematik PJOK tema diriku dan petunjuk pelaksanaan.

Instrumen yang digunakan dalam penelitian ini adalah angket dalam bentuk pernyataan terkait modul pembelajaran tematik PJOK tema diriku. Angket digunakan untuk mengumpulkan data hasil review dari ahli isi, ahli media, dan uji lapangan persiapan. Penelitian ini mengumpulkan data menggunakan teknik analisis deskriptif kuantitatif. Teknik analisis ini digunakan untuk mengolah data yang diperoleh melalui angket dalam bentuk Deskriptif persentase (Tegeh, I Made dan Jampel, 2017).

\section{HASIL DAN PEMBAHASAN Penelitian dan Pengumpulan Informasi}


Jurnal Kejaora: Jurnal Kesehatan Jasmani dan Olah Raga

ISSN: 2541-5042 (Online)

ISSN: 2503-2976 (Print)

Volume 6 Nomor 1, Edisi April 2021

dengan menyesuaikan $\mathrm{KI}$ dan KD. Dari hasil pengembangan produk dihasilkan 4 permainan dimana pada kegiatan pembelajaran 2 terdapat 2 permainan dan kegiatan pembelajaran 4 terdapat 2 permainan. Permainan-permainan tersebut adalah permainan temukan aku dan permainan merangkai kata terdapat pada pembelajaran 2, permainan SENAMAN (Sebut Nama Teman) dan permainan pos cerdas terdapat pada pembelajaran 4 .

\section{Uji Lapangan Persiapan (Uji Kelompok Kecil)}

Uji lapangan persiapan ini dilakukan di 2 sekolah dengan jumlah keseluruhan menggunakan 6 subjek yaitu: SD $\mathrm{N} 2$ Penglatan dan SD N 5 Jineng Dalem.

\section{Revisi Produk Utama}

Berdasarkan hasil dari uji lapangan persiapan diperoleh presentase 96,84\% berada pada kualifikasi sangat baik sehingga dalam produk modul pembelajaran tematik PJOK kelas 1 SD tema diriku subtema aku dan teman baru dengan keterangan layak digunakan dengan revisi.

\section{Hasil Uji Validasi Produk oleh Ahli}

Uji validasi produk dalam penelitian ini menggunakan 2 orang ahli yaitu (1) ahli isi/ materi dilakukan oleh Bapak Dr. Made Agus Wijaya, S.Pd., M.Pd yang merupakan dosen Prodi Penjaskesrek FOK Undiksha, (2) ahli media dilakukan oleh Bapak I Gede Suwiwa, S.Pd., M.Pd. Hasil validasi oleh ahli isi/materi memperoleh presentase tingkat pencapaian $91,76 \%$ berada pada kualifikasi sangat baik. Dengan demikian pengembangan modul pembelajaran tematik PJOK kelas 1 SD tema diriku subtema aku dan teman baru ini memiliki kelayakan yang sangat baik dari segi aspek isi/materi. Hasil validasi oleh ahli media memperoleh presentase tingkat pencapaian $83,33 \%$ berada pada kualifikasi baik. Dengan demikian pengembangan modul pembelajaran tematik PJOK kelas 1 SD tema diriku subtema aku dan teman baru ini memiliki tingkat kelayakan yang baik dari aspek media.

\section{PEMBAHASAN}

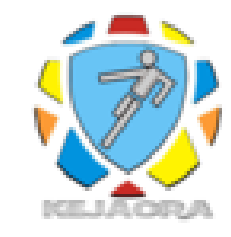

Berdasarkan hasil analisis kebutuhan tentang modul pembelajaran tematik PJOK dengan menyebarkan kuisioner kepada 10 orang guru PJOK di Kecamatan Buleleng, menunjukkan bahwa 9 guru (90\%) menyatakan mengalami kesulitan dalam menerapkan pembelajaran tematik khususnya PJOK dengan alasan: (1) kurangnya sosialisasi kepada guru PJOK dalam menerapkan pembelajaran tematik PJOK, (2) sarana dan prasarana disekolah pun juga belum memadai, (3) terbatasnya contoh-contoh kegiatan pembelajaran PJOK berbasis tematik, (4) buku pegangan guru tentang pembelajaran PJOK berbasis tematik masih secara umum dan belum lengkap, (5) proses pembelajaran menggunakan metode daring kurang efektif dalam melaksakan pembelajaran tematik PJOK. Hasil observasi menunjukkan bahwa 9 dari 10 guru PJOK mengharapkan adanya modul pembelajaran tematik PJOK di sekolah dasar agar tujuan dari pembelajaran dapat tercapai.

Hasil dari penelitian ini menunjukan bahwa validitas modul pembelajaran tematik PJOK yang dikembangkan ditinjau dari aspek isi dari ahli isi/materi berada pada kategori sangat baik dengan perolehan presentase $91,76 \%$. Perolehan validitas dengan kategori sangt baik dikarenakan kesesuaian antara materi tematik dengan permainan PJOK tema diriku subtema aku dan teman baru tersebut.

Adapun komentar dan saran yang diberikan oleh ahli isi terhadap modul pembelajaran tematik PJOK kelas 1 SD tema diriku subtema aku dan teman baru yaitu: 1) hasil evaluasi ahli media berada pada kategori baik dengan perolehan presentase sebesar $83,33 \%$. Hal ini dapat dilihat dari kesesuaian antara gambar dan aktivitas yang dilakukan. sedangkan validitas modul pembelajaran tematik PJOK ditinjau dari hasil uji lapangan persiapan (kelompok kecil) untuk Guru PJOK dengan perolehan presentase $96,85 \%$ dan peserta didik dengan perolehan 96,84 berada pada kategori sangat baik.

Berdasarkan hasil penelitian tersebut, maka modul pembelajaran tematik PJOK kelas $1 \mathrm{SD}$ tema diriku subtema aku dan teman baru dianggap valid dan layak menurut 
Jurnal Kejaora: Jurnal Kesehatan Jasmani dan Olah Raga

ISSN: 2541-5042 (Online)

ISSN: 2503-2976 (Print)

Volume 6 Nomor 1, Edisi April 2021

uji ahli isi/materi, uji ahli media, dan uji lapangan persiapan.

Hal ini sejalan dengan hasil penelitianpenelitian terdahulu yaitu penelitian yang dilakukan oleh (1) (Sari, 2015) mengenai pengembangan buku pelajaran tematik integratif berbasis nilai karakter disiplin dan tanggung jawab di sekolah dasar yang menunjukan bahwa buku pelajaran berkategori sangat baik dan hasil nilai karakter disiplin menunjukan uji $t=-3,110$ dengn $P$ sebesar 0,000 dan nilai karakter tanggung jawab menunjukan hasil uji $\mathrm{t}=-4,440$ dengan $P$ sebesar 0,003 . Selain itu, nilai hasil belajar menunjukan $100 \%$ peserta didik tuntas dalam pembelajaran. (2) (Estuwardani, 2015) mengenai pengembangan bahan ajar modul tematik integratif dalam peningkatan karakter peserta didik kelas 1 sekolah dasar menunjukkan bahwa bahan ajar yang dikembangkan menurut ahli materi dan ahli media berkategori "sangat baik" dengan Penerapan bahan ajar secara umum dapat terlaksana dengan kategori "baik", (3) (Arum \& Wahyudi, 2016) pengembangan modul pembelajaran tematik integratif dengan pendekatan saintifik subtema hubungan makhluk hidup dalam ekosistem untuk kelas 5 SD. modul terbukti valid berdasarkan uji pakar yang dilakukan. Penilaian validator aspek materi diperoleh rata-rata 3,96 dengan persentase $79,17 \%$. Validator aspek media mendapat ratarata 4 dengan persentase $80 \%$.

\section{KESIMPULAN}

Berdasarkan hasil penelitian disimpulkan bahwa modul pembelajaran tematik PJOK tema diriku pada kelas 1 SD di Kecamatan Buleleng layak digunakan ditinjau dari uji ahli isi, uji ahli media dan uji lapangan persiapan.

\section{UCAPAN TERIMA KASIH}

Dalam penyusunan skripsi ini peneliti banyak mendapat bimbingan, dorongan, dukungan, arahan, dan saran, serta motivasi dari berbagai pihak. Untuk itu pada kesempatan ini peneliti mengucapkan terima kasih kepada:

1. Prof. Dr. I Nyoman Jampel, M.Pd., Rektor Undiksha Singaraja yang telah

memberikan kesempatan kepada peneliti untuk mengikuti pendidikan di Program Studi Pendidikan Jasmani Kesehatan dan Rekreasi, Fakultas Olahraga dan Kesehatan.

2. I Ketut Budaya Astra, S.Pd., M.Or., Dekan Fakultas Olahraga dan Kesehatan, Universitas Pendidikan Ganesha, sekaligus sebagai pembimbing I yang telah banyak memberikan bimbingan, petunjuk, bantuan, dan dorongan, serta motivasi dalam penyusunan skripsi ini.

3. I Gede Suwiwa, S.Pd., M.Pd., Koordinator Program Studi Pendidikan Jasmani Kesehatan dan Rekreasi, Jurusan Pendidikan Olahraga, Fakultas Olahraga dan Kesehatan, Universitas Pendidikan Ganesha, yang telah memberikan kesempatan kepada saya untuk mengikuti pendidikan pada Program Studi Pendidikan Jasmani, Kesehatan, dan Rekreasi.

4. Staf Dosen dan pegawai di Program Studi Pendidikan Jasmani Kesehatan dan Rekreasi, yang selama ini telah banyak memberikan ilmu pengetahuan dan motivasi sebagai bekal menjalankan kehidupan di dalam masyarakat.

5. Keluarga besar yang telah memberikan dukungan dalam bentuk moril dan materi dalam hal penyusunan skripsi ini

6. Semua pihak yang tidak mungkin peneliti sebutkan satu-persatu, yang telah banyak membantu kelancaran dalam proses penyusunan skripsi ini

\section{DAFTAR PUSTAKA}

Arum, T. S., \& Wahyudi, W. (2016). Pengembangan Modul Pembelajaran Tematik Integratif Subtema Hubungan Makhluk Hidup Dalam Ekosistem Pendekatan Saintifik Untuk Kelas 5 SD. Scholaria : Jurnal Pendidikan Dan Kebudayaan.

https://doi.org/10.24246/j.scholaria.20 16.v6.i3.p239-250

Estuwardani. (2015). Pengembangan Bahan Ajar Modul Tematik-integratif Dalam Peningkatan Karakter Peserta Didik Kelas I Sekolah Dasar. Jurnal 
Jurnal Kejaora: Jurnal Kesehatan Jasmani dan Olah Raga

ISSN: 2541-5042 (Online)

ISSN: 2503-2976 (Print)

Volume 6 Nomor 1, Edisi April 2021

Pendidikan

Karakter. https://doi.org/10.21831/jpk.v0i2.8620 Huraibi, Chabib, Zain, C., \& Indahwati, N. (2018). Implementasi model pembelajaran kooperatif tipe STAD dan TGT terhadap motivasi belajar siswa dalam pembelajaran PJOK. 583-586.

Kadir, A. \& H. A. (2015). Pembelajaran Tematik. PT RAJAGRAFINDO PERSADA.

Maulana Arafat Lubis, M. P. (2016). Pembelajaran Tematik DI SD/MI Pengembangan Kurikulum 2013. In A. C (Ed.), CEUR Workshop Proceedings (pertama, Vol. 13, Issue 1). Katalog Dalam Terbitan (KDT) @

Mukhlis, M. (2012). Pembelajaran Tematik Pembelajaran Tematik Mohamad Muklis STAIN Samarinda. Fenomena, IV(20), 63-76.

Nafi, I., Muakibatul, H., \& Mudiono, A. (2016). Pengelolaan Kelas Dalam Pembelajaran Tematik di Sekolah Dasar. Jurnal Pendidikan, 1(5), 901904.

Pgmi, J., Tarbiyah, F., \& Keguruan, D. (2015). Tematik Sd. 2, 34-49.

Rahayu. (2016). Survei Tingkat Kemajuan Pendidikan Jasmani, Olahraga, Dan Kesehatan Di Sma, Smk, Dan Ma Negeri Se-Kabupaten Gresik. Jurnal Pendidikan Olahraga Dan Kesehatan, 3(3), 834-842.

Samsudin. (2008). Pembelajaran Pendidikan Jasmani Olahraga dan Kesehatan SMA/MA (Pertama, C). Prenada Media Group.

Sari, P. (2015). Pengembangan Buku Pelajaran Tematik-Integratif Berbasis Nilai Karakter Disiplin Dan Tanggung Jawab di Sekolah DasaR. Jurnal Prima Edukasia. https://doi.org/10.21831/jpe.v3i1.4070

Sukayati. (2009). Pembelajaran Tematik di $S D$ (A. Waluyati (ed.)). PPPPTK Matematika.

Tegeh, I Made dan Jampel, I. N. (2017). Metode Penelitian Pengembangan. UNDIKSHA.
Tirtoni, F. (2018). Pembelajaran Terpadu di Sekolah Dasar (S. B. M. T. M. Santika (ed.); Septi Budi). Umsida Press.

Utama, A. M. B. (2011). Pembentukan Karakter Anak Melalui Aktivitas Bermain Dalam Pendidikan Jasmani. Jurnal Pendidikan Jasmani Indonesia, 8(1), 1-9. 